\title{
LA DEMOCRACIA ESTÁ EN LOS DETALLES: APROXIMACIONES Y ACTUALIZACIÓN DEL DEBATE SOBRE LA RENDICIÓN DE CUENTAS
}

DEMOCRACY IS IN THE DETAILS: APPROACHES AND UPDATE OF THE DEBATE ON THE ACCOUNTABILITY

Alejandro Hernández-Luis ${ }^{1}$

\section{Resumen}

La rendición de cuentas es un valor fundamental para cualquier sistema político. En la actualidad es comprendida como una virtud y como un mecanismo para lograr varios elementos importantes de la gobernabilidad. Se entiende que los ciudadanos deben tener el derecho de saber qué acciones se han tomado en su nombre, así como también deben contar con los medios para tomar acciones correctivas cuando los funcionarios públicos actúan de manera ilegal, inmoral o injusta. Además, los ciudadanos deben tener la posibilidad de obtener una reparación o compensación cuando el Estado abusa de sus derechos o no reciben los beneficios públicos que les corresponden. En el presente trabajo se realiza una revisión de los principales abordajes de la rendición de cuentas que se han realizado en los últimos años, con el objetivo de hacerlos dialogar y analizar sus potencialidades dentro de la caja de herramientas de los sistemas políticos latinoamericanos.

\section{Palabras clave}

Estado, gobernabilidad, gobernanza, responsabilidad.

\section{Abstract}

Accountability is a fundamental value for any political system. Nowadays it is understood as a virtue and as a mechanism to achieve several important elements of governance. It is understood that citizens should have the right to know what actions have been taken in their name, as well as must have the means to take corrective actions when public officials act in an illegal, immoral or unfair manner. In addition, citizens should have the possibility of obtaining compensation when the State abuses their rights or does not receive the public benefits that correspond to them. In the present work, a review of the main approaches to the rendering of accounts that have been carried out in recent years is carried out, in order to make them discuss and analyze their potential within the toolbox of Latin American political systems.

\section{Keywords}

State, governability, governance, accountability.

\footnotetext{
${ }^{1}$ Facultad Latinoamericana de Ciencias Sociales (FLACSO-Ecuador). Correo electrónico: oahernandezfl@flacso.edu.ec.
} 


\section{Introducción}

En la comprensión actual del sistema político, hay dos consensos que son de suma importancia. En primer lugar, se destaca que la mayor parte del mundo señala a la democracia como la forma de gobierno normativamente preferible; y en segundo, sobresale la existencia de un vínculo íntimo entre democracia y rendición de cuentas. En este escenario de globalización, calificar un caso específico como «democrático» o no, tiene consecuencias morales y prácticas muy concretas. Es por ello que muchos de los esfuerzos académicos de los últimos tiempos están dirigidos a precisar el alcance de ambos términos.

La democracia moderna se puede describir como una concatenación de relaciones entre ciudadanos y actores estatales; o dependiendo de la literatura: principal y agente o foro y actor (Olsen, 2017; Strom, 2000, 2003; Bovens, 2007, 2010). Las personas (principal o foro) en una democracia, han transferido su soberanía a representantes populares (agente, actor), quienes, a su vez, transfieren la redacción y aplicación de leyes y políticas, al Estado. Luego, los ministros, delegan la ejecución de sus tareas a los miles de servidores públicos de su cartera $y$, en ocasiones, estos también delegan parte de sus tareas a otras instituciones, más o menos independientes. Cada eslabón de esta cadena busca monitorear la ejecución de las tareas públicas delegadas llamando a rendir cuentas (rendición de cuentas vertical burocrática).

Al final de la cadena están los ciudadanos que, tradicionalmente, juzgan la conducta de los funcionarios públicos y manifiestan su descontento al votar por otros representantes populares (rendición de cuentas vertical electoral). Estas han sido las principales apuestas de control de la democracia representativa. Por otra parte, la tradición republicana, aportó el control del poder interestatal a través del sistema de pesos y contrapesos e instituciones de balance: ejecutivo, legislativo y judicial (rendición de cuentas horizontal). Solo con la exposición de estos elementos básicos, es posible percatarse de que la rendición de cuentas es esencial para el proceso democrático; aunque también puede ser importante para otro tipo de sistema político.

En los últimos tiempos se ha revitalizado el debate sobre la rendición de cuentas y ha ganado centralidad - nuevamente - este concepto. Esto ha tenido lugar, a nuestro criterio, por dos factores: 1) la poca efectividad que demostraron los mecanismos de rendición de cuentas tradicionales (vertical burocrático, vertical electoral y horizontal de balance), ha generado la necesidad de plantearse nuevas formas de control e interacciones; y 2) la pérdida de polaridad de los conceptos representación y participación, ha provocado la articulación de sus lenguajes a través de procesos de innovación del control democrático.

Si bien es cierto que hay consenso generalizado sobre la rendición de cuentas como valor fundamental de la democracia, hay menos acuerdo sobre cómo se logra una rendición de cuentas efectiva. Es frecuente encontrarse, de esta manera, en el discurso político y en la literatura académica, además de con las metáforas espaciales clásicas de la ciencia política (vertical y horizontal), a un sinnúmero de recientes adjetivaciones; tales como: social, societal, transversal, diagonal, corporativa, inversa, retrospectiva, entre muchas otras.

En el presente trabajo investigativo nos proponemos realizar una revisión de la evolución y estado actual del concepto «rendición de cuentas», así como intentaremos abordar las aproximaciones teóricas que consideramos de mayor utilidad en la comprensión de un término que se muestra, en ocasiones, esquivo y evasivo.

\section{Democracia: representación, participación y rendición de cuentas}

La democracia, entendida de manera general, significa, «gobierno de la gente». Este es un elemento común a todos los usos de la palabra desde la época clásica. Además, todos los usos del término presuponen también soberanía. De esta manera, un sistema político, por grande o pequeño que sea, debe disfrutar de cierto grado de autogobierno para que la democracia se realice (Coppedge et. al., 2011). Más allá de estos elementos básicos, no existe consenso sobre lo que significa la democracia. En ese sentido, no es objetivo de este trabajo intentar aportar otra - quizás estéril-definición. Al contrario, se propone la utilidad de reconocer la indeterminación del concepto y ver su contenido como un producto cambiante de un debate continuo y abierto; así como una lucha por ideales normativos y arreglos institucionales (Olsen, 2017).

El debate sobre la democracia se ha intensificado y enriquecido desde la finalización de la Guerra Fría. Como explican Gurza e Isunza (2011), durante todo ese período las severas restricciones a los intentos de desarrollar críticas internas y teorías sustantivas de la 
democracia, congelaron también las posibilidades de un análisis plural. Esto llevó a afirmar a algunos sectores de la literatura académica, que el término "democracia», había perdido su significado (Hanson, 1989). El fin de este conflicto y los procesos de democratización latinoamericanos de los últimos años del siglo XX, aportaron interesantes innovaciones institucionales que revitalizaron la discusión. De ahí que la democracia continúe siendo un término "esencialmente disputado», sobre todo porque sus contenidos reflejan posiciones teóricas y metodológicas diversas, así como disímiles concepciones de la vida pública y proyectos de acción política (Monsiváis, 2015).

La falta de acuerdos sobre el significado de la democracia probablemente sea un problema que no tenga solución. La crítica interna actual ha situado en el centro de la discusión la necesidad de abordar el carácter ambiguo de los estándares y los principios fundacionales de la democracia e interpretarla como un concepto histórico, espacial y contextual; en lugar de como un concepto universal (Olsen, 2017). En este proceso, es interesante observar como la participación y la representación, dos términos que tradicionalmente se encontraban alineados a coordenadas opuestas, se han resignificado de modo recíproco y otros conceptos que antes eran aparentemente insustanciales para la crítica, como el de rendición de cuentas, comenzaron a ganar centralidad (Gurza e Isunza, 2011, 2015).

Tradicionalmente la representación se encontraba relacionada con modelos electorales o minimalistas de la democracia, mientras que la participación, esencialmente criticó a los modelos representativos, realizaba propuestas democráticas más ambiciosas. Al finalizar la Guerra Fría comenzaron a desaparecer las condiciones históricas que provocaron esta polarización conceptual. En primer lugar, ocurre una disociación entre los conceptos de gobierno representativo y representación política, incitada por procesos de pluralización democrática de la representación; haciéndola sensible, por lo tanto, a exigencias de legitimidad. En segundo lugar, el fin de la mencionada circunstancia histórica, también modificó el lugar de la participación en la crítica democrática. Expresión de ello, son las experiencias de innovación que han sido la fuerza motriz para la revisión de los postulados fundamentales de las teorías participativas (Gurza e Isunza, 2011).

La pérdida de polaridad entre ambos conceptos ha provocado una articulación de sus lenguajes, ubicándolos en un registro analítico, que podemos identificar como «mixto». De esta forma, conceptos asociados al dialecto participativo tales como «sociedad civil», «movimientos sociales» y "ciudadanos», se han vuelto compatibles con "gobernanza», «transparencia», «controles democráticos», «eficiencia» y «rendición de cuentas», más propios, tradicionalmente, del lenguaje representativo. Por supuesto esto no ha estado exento de críticas y sospechas, llegando a ser acusado este sincretismo de "conflictividad perversa» (Dagnino, 2004) o "passepartout semánticos» (Cornwall y Coelho, 2007). Sin embargo, coincidiendo con Gurza e Isunza (2011), consideramos que estas transformaciones han traído una ráfaga de aire fresco a la teoría democrática, al debate intelectual y a la formulación y disputa pública de demandas distributivas de los actores sociales.

En este marco, la incorporación de la idea de «rendición de cuentas», tanto en el debate sobre la pluralización de la representación, como en el campo de los estudios sobre participación, constituye un virtuoso intento en la promoción de nuevas estrategias conceptuales. Así, la rendición de cuentas se ha convertido, nuevamente, en una preocupación democrática fundamental ( $\mathrm{O}^{\prime}$ Donell, 2007; Peruzzotti y Smulovitz, 2001; Bovens, 2007, 2010; Peters, 2007; Olsen, 2017; Gurza e Isunza, 2010). Los arreglos de rendición de cuentas existentes fueron revisitados, cuestionados y se han propuesto otros nuevos. De aquí ha resultado un desafío interesante para la teoría de la rendición de cuentas, consistente en, explorar cómo las democracias enfrentan las tensiones entre concepciones múltiples, controvertidas y dinámicas de los estándares de control democrático.

De esta manera se ha llegado a un acuerdo, bastante generalizado, sobre la necesidad de instituciones bien desarrolladas que garanticen el control democrático y que, por el contrario, la falta de relaciones y procesos efectivos de rendición de cuentas, socava la democracia (Olsen, 2017). Menos acuerdo hay sobre cómo se logra una rendición de cuentas efectiva y qué arreglos institucionales, pueden y deben usarse para responsabilizar a los titulares de los cargos; es decir, en qué medida y de qué manera, la rendición de cuentas depende de los entornos institucionales en los que se rinde cuentas y que procesos tienen lugar.

Una actitud crítica está en el centro de la voluntad democrática $y$, los procesos de rendición de cuentas, proporcionan nuevas formas para interpretar, debatir y cambiar visiones del mundo, criterios normativos, 
distribuciones de autoridad y poder, responsabilidad y concepciones de roles e identidades legítimas.

\section{Rendición de cuentas: historia y problemas actuales}

Desde la creación del Estado moderno surgió la preocupación por su poder y las formas de limitarlo. El poder del Estado se presentó como un caso especial de dominación, mediante el cual la voluntad manifiesta del dominador o los dominadores, influye sobre los actos de otros; de manera que estos actos tienen lugar como si los dominados los hubieran adoptado por sí mismos y, como máxima de su obrar, tuviesen el contenido del mandato (Weber, 2002). Con la instauración de esta organización política, los individuos comienzan a enfrentarse a una compleja contradicción. De una parte, las personas tienen el deseo de no vivir en un estado de naturaleza violento, del tipo hobbesiano, donde existe una lógica de supervivencia mediante la guerra de todos contra todos; y por la otra, tienen miedo de vivir en un estado que tiene la posibilidad constante de abusar de su poder, y que es el encargado de proveer bienes públicos básicos y soluciones colectivas vinculantes para las propias personas. El origen de esta tensión está dado en que, el individuo desea que las decisiones vinculantes que se tomen, sean lo suficientemente efectivas como para alcanzar los fines deseados y, a su vez, existan los controles necesarios para garantizar la protección ante las consecuencias nocivas, que esas soluciones colectivas (estatales), puedan provocar a los intereses individuales (O'Donell, 2007).

De esta manera, se ha vuelto un lugar común, argumentar que existe la necesidad de restringir el poder del Estado y evitar que la población sea seducida por demagogos. También se ha argumentado que «la voluntad de la gente» es una ficción: los demos, en el sentido de una masa amorfa, nunca gobiernan grandes asociaciones (Weber, 2002). En este punto se puede llegar a pensar que la democracia es la forma de gobierno que resuelve los problemas mediante el control efectivo del poder de los funcionarios estatales por parte de los ciudadanos (Przeworski, 2002). De hecho, para algunos autores esenciales de la teoría democrática, como Robert A. Dahl (1989), esa capacidad de control, es uno de los elementos definitorios del concepto. La «rendición de cuentas» se encuentra, en este marco, como un conjunto de principios y mecanismos que tienen como objetivo principal controlar el poder, ya sea desde agencias del propio estado, desde la ciudadanía, la sociedad civil o entidades internacionales.

Histórica y semánticamente, la rendición de cuentas ha estado asociada a las palabras «responsabilidad»y «contabilidad» (en el sentido literal de contabilidad). El concepto contemporáneo ha podido rastrearse hasta el reinado de Guillermo I, en las décadas posteriores a la conquista normanda de Inglaterra (Bovens, 2010); es decir, unos siglos antes de la formación de los Estados modernos. En el año 1085, el rey exigió a todos los propietarios de su reino que rindieran cuentas de lo que poseían. Estas posesiones fueron evaluadas y enumeradas por agentes reales en los llamados «Libros Domesday». Estos libros enumeraban lo que estaba en el reino y recogían los juramentos de lealtad de los terratenientes a la corona. De esta manera, se generaba un efecto de reconocimiento por parte del rey, basado en el hecho de que los propietarios eran agentes autónomos que podían y estaban dispuestos a cumplir con la obligación moral de dar cuenta de sus acciones, siempre que se les pidiese que lo hicieran (Dubnick, 2007). Por su lado, Schedler (2004) explica que las cuentas son, etimológicamente, cercanas a los cuentos. Se cuentan números y también se cuentan historias; ambigüedad que sostiene dos de las dimensiones de la rendición de cuentas: la informativa y la argumentativa.

La noción literal de «dar cuentas», como se mencionó, también está conectada con el concepto de responsabilidad como elemento definidor de las relaciones entre soberano y sujeto, principal y agente (Olsen, 2017), o foro y actor (Bovens, 2010). El término responsabilidad se puede usar de diferentes maneras; cada una con diferentes implicaciones. Sin embargo, hay dos dimensiones de la responsabilidad que deben ser tomadas en cuenta en todo proceso de rendición de cuentas: la responsabilidad de actuar conforme a los compromisos adquiridos y; la responsabilidad de informar sobre estas acciones, justificarlas y asumir sus consecuencias (Thede, 2010).

En los siglos transcurridos desde el reinado de Guillermo I de Inglaterra hasta la actualidad, la rendición de cuentas se ha ido liberando lentamente de su esclavitud etimológica con la contabilidad. En el discurso político contemporáneo, el término ya no transmite una imagen reducida de contabilidad y administración financiera, sino de promesas de una gobernabilidad democrática, justa y equitativa (Bovens, 2007). Además, la relación originaria se ha revertido casi por completo. Ya no se trata de soberanos que hacen rendir cuentas a sus súbditos, sino al contrario: son las autoridades las responsables de 
hacerlo a sus ciudadanos.

La noción de rendición de cuentas, como apunta Schedler, puede parecer que indica un acto voluntario, «una concesión generosa del soberano que rinde cuentas por virtud y voluntad propia, no por necesidad» $(2004,3)$. Sin embargo, la idea de rendición de cuentas que abordamos en este trabajo está más relacionada con el término «accountability» ${ }^{2}$, es decir, la rendición obligatoria de cuentas.

En el discurso político y académico contemporáneo, esta idea de "rendición de cuentas», a menudo sirve como un paraguas que abarca varios conceptos distintos, tales como: transparencia, equidad, democracia, eficiencia, capacidad de respuesta, responsabilidad e integridad. De igual manera, también es utilizado indistintamente como sinónimo de buen gobierno o comportamiento virtuoso (Bovens, 2007). Como resultado de esta expansión conceptual, algunos autores han llegado a apuntar que la rendición de cuentas se ha convertido en un término general para cualquier mecanismo que haga que las instituciones poderosas respondan a sus públicos particulares (Mulgan, 2003). Esto ha impedido el progreso empírico en este amplio campo de estudios, el cual ha estado marcado por discusiones circulares donde cada autor intenta redefinir el concepto a su manera (Bovens, 2010).

Una posible razón por la cual la rendición de cuentas se ha vuelto tan prominente entre su clase sinonímica, puede estar relacionada con su asociación discursiva con lo que se percibe como altos valores públicos. A medida que el concepto de rendición de cuentas se entrelazó narrativamente con las promesas de democracia, justicia, control y mayor desempeño administrativo, su condición de virtud pública también aumentó; al punto que ha llegado a dominar a sus conceptos relacionados. La centralidad de la rendición de cuentas en la actualidad, es indiscutible (Dubnick, 2014). Bovens (2010) ha notado, sin embargo, que la rendición de cuentas no es solo una virtud; sino que también es un mecanismo e instrumento de poder administrativo y político que funciona con el fin de lograr el cumplimiento de las políticas. Estos dos aspectos de la rendición de cuentas, están estrechamente relacionados.
El desarrollo de la rendición de cuentas como una virtud se encuentra mayoritariamente, en el discurso académico y político estadounidense. En este, la rendición de cuentas se utiliza como un concepto normativo, es decir, como un conjunto de estándares para la evaluación del comportamiento de los actores públicos. El concepto se entiende como una cualidad positiva de las organizaciones o los funcionarios. Por lo tanto, los estudios de rendición de cuentas a menudo se centran en la indagación de estándares y evaluación del comportamiento real y activo de los agentes públicos. La rendición de cuentas en este sentido amplio es básicamente un concepto evaluativo, no analítico. También, en ese sentido, es un concepto esencialmente controvertido y discutible, ya que no existe un consenso general sobre los estándares para el comportamiento responsable.

Por otra parte, los debates académicos europeos, australianos, canadienses y latinoamericanos, utilizan la rendición de cuentas en un sentido descriptivo. En estos debates, el concepto es utilizado como un "mecanismo", es decir, como una relación o arreglo institucional en el que un principal, agente o institución puede responsabilizar a otro agente o institución ( $\mathrm{O}^{\prime}$ Donell, 2007; Mulgan, 2003). Por lo tanto, el centro de los estudios de rendición de cuentas no es tanto el comportamiento de los agentes públicos, sino la forma en que operan estos arreglos institucionales. Esta forma de análisis corre el riesgo de no centrarse en si los agentes han actuado de manera responsable o no; sino en si son o pueden ser responsabilizados ex post facto (Bovens, 2007) por los foros de rendición de cuentas.

Tanto el concepto más amplio, en el que la rendición de cuentas se ve como una virtud personal u organizacional, como el concepto más restringido, en el que se define como una relación o mecanismo social, son útiles para el estudio y el debate sobre la gobernabilidad democrática (Bovens 2010); pero por razones diferentes. La rendición de cuentas como virtud es importante, ya que proporciona legitimidad a los funcionarios y a las organizaciones públicas. Los gobiernos se enfrentan a un público cada vez más crítico y el ejercicio de la autoridad no se da por sentado. La confianza en el gobierno cada vez suele ser más frágil y un gran número de democracias

\footnotetext{
${ }^{2}$ En este trabajo no revisamos las diferencias idiomáticas entre «accoutability» y «rendición de cuentas». Para profundizar en este aspecto se puede revisar el texto de Andreas Schedler referenciado.
} 
experimentan una erosión gradual del apoyo político (O'Donell, 2007; Peruzzotti y Smulovitz, 2002). La rendición de cuentas democrática, en el sentido de una gobernanza transparente, receptiva y responsable, tiene entonces como objetivo, asegurar la confianza pública en el gobierno y cerrar la brecha entre ciudadanos y representantes. Por otra parte, la rendición de cuentas como mecanismo es instrumental para lograr una gobernanza responsable. Los arreglos de rendición de cuentas aseguran que los funcionarios $u$ organizaciones públicas permanezcan en el camino virtuoso. Por lo tanto, en última instancia, la rendición de cuentas como mecanismo también es importante porque contribuye a la legitimidad de la gobernanza (Bovens, 2010).

En síntesis, como un valor público apreciado (virtuoso), la rendición de cuentas ha surgido como una fuerza moral que puede ser utilizada - y a menudo lo es - para promover y fomentar la aplicación de mecanismos de cumplimiento e instrumentos de cambio. Esta fuerza moral puede ejercerse a través de la presión externa que enfatiza la conveniencia de una gobernanza responsable y los esfuerzos para inculcar e internalizar un compromiso ético con la democracia dentro de las agencias públicas (Dubnick, 2014).

\section{Aproximaciones teóricas}

La forma más simple de rendición de cuentas es el requisito de que una organización de la administración pública presente una «cuenta» de lo que ha hecho. El informe debe hacerse a alguna organización externa e independiente -un parlamento/asamblea, un auditor, o a la ciudadanía-, de modo que la evaluación pueda ser razonablemente pública y objetiva. La cuenta puede ser financiera, o puede expresarse en términos de servicios prestados, así como de los éxitos y fracasos de una determinada política o programa. En cualquier caso, implica «hacer público lo que se ha hecho en nombre público» (Peters, 2007, p.16). Esta forma resalta la noción de que, en el nivel más básico, la rendición de cuentas se trata de transparencia, de hacer posible que los actores externos a una organización pública identifiquen y cuestionen lo que en ella sucedió.

Podemos resumir esquemáticamente la rendición de cuentas así: "A rinde cuentas a B cuando está obligado a informarle sobre sus acciones y decisiones (pasadas o futuras), a justificarlas y a sufrir el castigo correspondiente en caso de mala conducta» (Schedler, 2004, p. 20).
Esta manera sintética de conceptualizar, muestra las tres dimensiones que el término abarca: información, justificación y sanción. Sin embargo, este planteamiento que puede parecer simple en primera instancia, se hace complejo en la medida en que se profundiza en cada una de estas dimensiones.

En principio, la rendición de cuentas abarca dos tipos de cosas: (1) información sobre decisiones de funcionarios públicos y (2) explicación de esas decisiones. De esta forma, exigir cuentas está relacionado tanto con tareas de vigilancia y monitoreo para la búsqueda de hechos y generación de evidencias; como con la idea de supeditar el poder al imperio de la razón y no solo al imperio de la ley. Es importante señalar que la rendición de cuentas no es una relación que transita en un solo sentido, sino que debe representar un intercambio entre actores, es decir, los que exigen y los que rinden cuentas. En el núcleo de este ejercicio de control democrático está el diálogo crítico; tal como señala Schedler $(2004$, p. 15) «la rendición de cuentas no es un derecho de petición [...] es un derecho a la crítica y al diálogo».

Sin embargo, la rendición de cuentas alcanza más que la generación de datos y el intercambio de argumentos entre actores, en ocasiones también contiene elementos de coacción y castigo. Este ha sido un punto de discusión, ya que algunas investigaciones no consideran la posibilidad de sanciones como un elemento constitutivo. En estas, se argumenta que las etapas de informar, justificar y debatir por si solas, son suficientes para calificar una relación como un mecanismo de control democrático.

Por otra parte, autores como Mulgan (2003, p. 9), Strom (2003, p. 62) y Peruzzotti y Smulovitz (2002, p. 35), con los cuales coincide esta investigación, argumentan que la posibilidad de sanciones de algún tipo, constituye un elemento constitutivo de la rendición de cuentas y que debería incluirse en cualquier definición de este concepto. La posibilidad de sanciones -no la imposición real de sanciones- hace la diferencia entre la provisión de información no comprometida y la obligación de rendir cuentas. Sin embargo, «sanción» tiene una connotación bastante formal, legal y excluyente (Bovens, 2010). Por ejemplo, no tomaría en consideración a los defensores del pueblo como un foro de rendición de cuentas, ya que en muchos países no tienen la autoridad para imponer sanciones formales; pero que, por otra parte, pueden llegar a ser muy efectivos para obtener compensaciones o reparaciones. 
Por lo tanto, quizás sea conveniente el uso de una expresión algo más neutral como, por ejemplo: el actor puede enfrentar consecuencias. Estas consecuencias pueden ser altamente formalizadas, tales como multas, medidas disciplinarias, recursos civiles o incluso sanciones penales, pero también pueden basarse en reglas no escritas, como en el caso de la responsabilidad política de un ministro ante el parlamento, donde la consecuencia puede extenderse hasta llegar a pedir la renuncia del ministro. En otras ocasiones, las consecuencias negativas serán implícitas o informales, como en el hecho de tener que rendir cuentas frente a las cámaras de televisión, lo que puede alcanzar la desintegración de la imagen pública y la carrera de un funcionario; resultado de la publicidad negativa generada en el proceso (Olsen, 2017; March y Olsen, 1995; Schedler, 2004).
Lo que importa en esta dimensión es el esfuerzo por asegurar el cumplimiento de las normas. Esto implica que los actores que exigen cuentas no solo demandan información y justificación, sino que tienen la posibilidad y capacidad de castigar o generar consecuencias ante el comportamiento inadecuado de los servidores públicos; aunque en ocasiones estos castigos o consecuencias, solo tengan un carácter simbólico. Los ejercicios de rendición de cuentas que no tienen esta capacidad, suelen ser vistos como ejercicios débiles (Shedler, 2004).

En sentido amplio, la rendición de cuentas se dirige hacia todos los profesionales de la política, exceptuando los funcionarios «bajos» y los jueces (Schedler, 2004). De igual manera, se incluyen también los funcionarios de los

Tabla 1. Rendición de cuentas. Criterio, objeto y ante quién.

\begin{tabular}{|c|c|c|}
\hline Criterio & Objeto de la rendición & Ante quiénes \\
\hline Político & $\begin{array}{l}\text { Procesos de toma de decisión; resultados } \\
\text { sustantivos de las políticas públicas; calidades } \\
\text { y capacidades personales de políticos y } \\
\text { funcionarios. }\end{array}$ & \multirow[t]{2}{*}{$\begin{array}{l}\text { Ciudadanos, medios de comunicación, } \\
\text { partidos políticos y asociaciones civiles. }\end{array}$} \\
\hline Moral & $\begin{array}{l}\text { Actuación de manera apropiada en términos } \\
\text { de normas sociales prevalecientes. }\end{array}$ & \\
\hline Administrativo & $\begin{array}{l}\text { Relación acto burocrático - procedimiento } \\
\text { establecido - resultado deseado - eficiencia } \\
\text { razonable. }\end{array}$ & \multirow{2}{*}{$\begin{array}{l}\text { Agencias públicas especializadas tales } \\
\text { como: agencias anticorrupción, defensores } \\
\text { del pueblo y cortes administrativas. }\end{array}$} \\
\hline Financiero & $\begin{array}{l}\text { Relación uso de dinero público - disposiciones } \\
\text { legales vigentes; estándares de transparencia, } \\
\text { austeridad y eficiencia. }\end{array}$ & \\
\hline Profesional & $\begin{array}{l}\text { Aplicación de las normas del profesionalismo } \\
\text { (en ámbitos como el médico, académico y } \\
\text { judicial). }\end{array}$ & Comisiones de ética o cortes disciplinarias. \\
\hline Legal & Cumplimiento de la ley. & \multirow{2}{*}{ Cortes judiciales. } \\
\hline Constitucional & Constitucionalidad. & \\
\hline
\end{tabular}

Elaboración propia en base a texto de Schedler, 2004.

Se puede apreciar que el campo de la rendición de cuentas es amplio y variado. Debido a ello, se han desarrollado metáforas espaciales (O'Donell, 2001, 2002; Gurza e Isunza 2010; Goetz y Jenkins, 2001) para ayudar a la comprensión de las relaciones entre actores sociales y estatales (rendición de cuentas «vertical»), entre actores estatales (rendición de cuentas «horizontal») y entre actores estatales y ciudadanos que actúan dentro del mismo aparato estatal (rendición de cuentas «diagonal»). Estas, no obstante, no son las únicas formas de rendición de cuentas de las que habla la literatura; de hecho, sería prácticamente imposible, en un trabajo de este tipo, mencionar y caracterizar todas las adjetivaciones que el término ha adquirido recientemente.

El criterio de selección para revisión y profundización 
de las tres formas antes mencionadas, responde, fundamentalmente, a que estas son las que recientemente han reconocido los gobiernos de la región en un instrumento internacional, que se ha dado a conocer como "Carta Iberoamericana de Gobierno Abierto» ${ }^{3}$ (CLAD, 2016).

\section{Rendición de cuentas vertical (electoral y societal)}

En los regímenes democráticos se encuentran generalmente dos vertientes del control vertical: electoral y social. El concepto de control vertical no define, de antemano, la dirección en la que fluye el control, lo cual representa un problema. Los regímenes autoritarios, y en no pocas ocasiones los democráticos, suelen preocuparse más por la rendición de cuentas que fluye de arriba hacia abajo, que es la rendición de cuentas burocrática y descuidan la que fluye de abajo hacia arriba, es decir, la electoral y la social (Schedler, 2004).

Uno de los trabajos más referenciados sobre la rendición de cuentas (vertical) electoral es el de Bernard Manin, Adam Przeworski, y Susan C. Stokes (2002). Para estos autores, desde el punto de vista de la rendición de cuentas, las elecciones sirven para responsabilizar a los gobiernos por los resultados de sus acciones pasadas. De esta forma, con sus mecanismos de anticipación y predicción de los juicios de los votantes, los gobiernos suelen actuar eligiendo políticas que, a su juicio, serán evaluadas positivamente por los ciudadanos en el momento de las próximas elecciones.

Independientemente de que las personas no puedan controlar a los gobiernos obligándolos de forma directa a cumplir mandatos, si pueden hacerlo cuando les anticipan a los funcionarios que tendrán que rendir cuentas por sus acciones. Es así que, los gobiernos son «controlables» cuando los votantes son capaces de distinguir si los representantes públicos están actuando según sus intereses y puedan sancionarlos debidamente. De esta manera, aquellos funcionarios que actúan conforme al mejor interés de los ciudadanos, logran la reelección y aquellos que no lo hacen, la pierden. La rendición de cuentas electoral ocurre entonces cuando: (1) las personas votan para retener al funcionario que actúo en función de sus mejores intereses; y (2) el funcionario elige las políticas necesarias para ser reelecto (Manin, Przeworski y Stokes, 2002).

Para comprender con más detenimiento el problema de la rendición de cuentas electoral, se debe considerar cuales son usualmente los objetivos de los políticos. En la práctica, los políticos pueden no hacer nada que los ciudadanos no hubieran querido que estos hicieran; puede ser que tengan un gran espíritu cívico y se dediquen por completo al interés público. Pero también, los políticos pueden querer hacer algo diferente que termine siendo costoso para los ciudadanos. Por ejemplo, pueden trazarse objetivos que los ciudadanos no comparten, tales como la reelección o ganancias privadas. Los políticos pueden querer, además, perseguir sus propias creencias, incluso si estas difieren de las de los ciudadanos. Algunos pueden preocuparse más por avanzar en sus carreras contra otros políticos, ya sea dentro del gobierno o dentro del mismo partido. Otros pueden estar más preocupados por el reconocimiento de la comunidad regional o internacional. En todos estos casos, los políticos quieren algo que es perjudicial para los ciudadanos, en cuanto no está alineado a sus intereses. A esto, Manin, Przeworski y Stokes (2002) le llaman «rentas».

El problema está entonces en que los ciudadanos deben buscar hacer algo que les limite las rentas a los políticos y por el contrario lograr que hagan lo que los votantes desean. Esto puede alcanzarse mediante el uso de lo que se conoce como "voto retrospectivo». Este mecanismo funciona cuando los ciudadanos establecen estándares de desempeño para evaluar los gobiernos. Los estándares pueden ser infinitos y disímiles, por ejemplo, aumentar en un determinado porcentaje los ingresos personales de los ciudadanos; mejorar el transporte público y disminuir la violencia en una ciudad; e incluso pueden estar relacionados con la clasificación del equipo nacional (baseball, fútbol, etc.) a un evento internacional relevante. Si los funcionarios no logran satisfacer estos estándares definidos por los ciudadanos, estos votan en contra de los titulares del puesto público. Eso lo saben los gobiernos y si desean ser reelegidos, deben anticiparse a la decisión de los ciudadanos, haciendo todo lo posible por satisfacer sus criterios. Dado que los actores políticos, por lo general, desean efusivamente conservar sus puestos y que anticipan cuidadosamente la reacción del público como el medio para lograr el fin reelección; el electorado

\footnotetext{
${ }^{3}$ A excepción de los gobiernos de Nicaragua y Venezuela que no la suscribieron.
} 
mediante el voto retrospectivo tiene una herramienta con algún grado de efectividad para hacer ejercer el control electoral, aunque esta es ex post, no ex ante.

De esta forma queda claro que los ciudadanos usan el voto con el propósito de sancionar a los funcionarios utilizando la información sobre su desempeño; y de esta manera intentar que se comporten correctamente y sean honestos. Sin embargo, esta no es la única función que tienen las elecciones; el voto también puede ser utilizado de manera prospectiva. El «voto prospectivo» es usualmente identificado con aquel en donde los votantes comparan las promesas que los candidatos hacen hacia el futuro y la utilizan para elegir al que consideran la mejor opción. De hecho, está bastante incorporado dentro del imaginario democrático, que los ciudadanos desean elegir, a través del voto, a los mejores políticos y las mejores políticas. Pero uno de los grandes problemas de este tipo de control democrático, es que los ciudadanos tienen un instrumento - que utilizan una única vez en relativamente largos períodos -, para alcanzar dos objetivos: (1) seleccionar las mejores políticas y políticos e (2) inducirlos a comportarse correctamente mientras están en el cargo (Manin, Przeworski y Stokes, 2002).

Otro de los argumentos que impiden la eficacia del voto está en el hecho de que votar es una acción estratégica descentralizada (Peruzzotti y Smulovitz, 2002). Generalmente, no es posible que los ciudadanos coordinen la orientación de su voto, y por ello, es que no se puede determinar si los resultados electorales responden a la selección de mejores políticos y políticas (prospectivo) o a sancionar el comportamiento de determinado funcionario (retrospectivo). Se ha señalado, finalmente, que los déficits de información frecuentes en el ciudadano promedio son un difícil obstáculo en la evaluación adecuada del desempeño de las decisiones de gobierno; por lo que el voto no cumple de manera eficiente su función de control democrático (Manin, Przeworski y Stokes, 2002; Peruzzotti y Smulovitz, 2002).

Los problemas que presenta el voto como mecanismo de control, motivaron que el interés de estudio de formas verticales tomará en cuenta otras formas de control no electoral. En este escenario comenzó la discusión teórica sobre la rendición de cuentas social (o societal) y sus interacciones con los controles verticales tradicionales y también con los controles horizontales. La rendición de cuentas social se puede definir como «un mecanismo de control vertical, no electoral, de las autoridades políticas, basado en las acciones de un amplio espectro de asociaciones y movimientos ciudadanos, así como acciones mediáticas» (Peruzzotti y Smulovitz, 2002, p. 10). Esta definición es claramente diferenciadora de los mecanismos tradicionales de rendición de cuentas; no se trata de una sumatoria de votos (vertical), ni del sistema de pesos y contrapesos del Estado (horizontal). El mecanismo se sustenta en el accionar de sectores organizados de la sociedad civil y en los medios de comunicación que estén interesados y tengan capacidad de influencia en el sistema político y la burocracia pública. La rendición de cuentas social incorpora conceptos provenientes de la literatura sobre sociedad civil y esfera pública. De esta forma, el funcionamiento de asociaciones civiles, movimientos sociales, organizaciones no gubernamentales (ONGs) y medios de comunicación, aportan nuevos recursos al repertorio tradicional de las instituciones electorales y constitucionales para el control del gobierno y, además, puede compensar muchos déficits de esos mecanismos.

Las iniciativas de los actores de la rendición de cuentas social tienen por objeto «monitorear el comportamiento de los funcionarios públicos, exponer y denunciar actos ilegales de estos y activar la operación de agencias horizontales de control» (Peruzotti y Smulovitz, 2002, p. 32). Estas iniciativas pueden ser llevadas a cabo por medios institucionalizados o no institucionalizados. Es así que, por ejemplo, una acción institucionalizada puede ser una denuncia legal ante la Fiscalía o Contraloría u otro órgano de control; mientras que las no institucionalizadas pueden ser movilizaciones sociales o denuncias mediáticas que, por lo general, buscan establecer sanciones simbólicas. En síntesis, la rendición de cuentas social, suele apoyarse en tres tipos de estrategias: jurídica, movilizacional y mediática.

Luego de estas precisiones generales no es difícil percatarse de que la rendición de cuentas social también es un componente importante de la vida democrática. Esto no es nada nuevo, la idea de que una sociedad activa y organizada vigoriza la democracia es un planteamiento sostenido desde los inicios de la teoría democrática moderna. Sin embargo, el concepto de rendición de cuentas social es útil porque agrupa y agrega una serie de actividades sociales diversas que comparten características similares.

Finalmente, el trabajo de Peruzzotti y Smulovitz (2002) es interesante porque destaca dos aspectos originales de la rendición de cuentas social. El primero es que la orientación principal de las acciones que comprende este 
concepto no es la satisfacción de intereses materiales. Y, el segundo, es que las demandas de rendición de cuentas sociales suelen ser presentadas en lenguaje de legalidad y derechos. Ante la referida ineficiencia de los controles democráticos electorales y la posibilidad que tienen los controles sociales de activar controles horizontales. En el siguiente punto se realizará una revisión de estos últimos, sobre todo desde los aportes de Guillermo O'Donnell (2001, 2002).

\section{Rendición de cuentas horizontal}

El término «accountability horizontal» fue acuñado por Guillermo O'Donell. En este caso, no se trata del control del poder estatal por parte de la sociedad, que ha sido el más estudiado desde la ciencia política a través de investigaciones sobre el voto, las elecciones, el rol de la sociedad civil, los movimientos sociales y los medios de comunicación; sino, del control que se realiza entre agencias estatales ante acciones $u$ omisiones que se presuman como ilegales o corruptas. La rendición de cuentas horizontal se presenta de esta manera, como un subconjunto entre las múltiples interacciones que las agencias estatales emprenden entre sí.

Es conocido y repetido que la tripartición de poderes es uno de los elementos fundamentales del sistema democrático moderno. Sin embargo, si bien este aporte anglo-francés (Locke y Montesquieu) es de suma importancia para el funcionamiento de una democracia, en su formulación más simple, no garantiza por sí solo el control del poder estatal. De esto se percató James Madison, lo que lo llevó a proponer que los poderes podían mejorar el control mutuo, si cada uno de ellos tenía jurisdicción sobre importantes atribuciones de los otros (Fernández-Albertos, 2005). Es gracias a este aporte de Madison, que la Constitución norteamericana tiene el mérito de haber formulado la interpenetración parcial de los poderes, propugnando así, una autonomía relativa y el equilibrio entre estos.

Las constituciones democráticas contemporáneas han seguido el ejemplo de la de los Estados Unidos. Las relaciones provenientes de la interpenetración parcial entre los poderes se conciben regularmente como instancias de control mutuo o de intercambio; sin embargo, en ocasiones, estas relaciones interestatales originan conflictos; sobre todo, cuando una agencia, considera que otra ha sobrepasado ilegalmente su jurisdicción. Las situaciones de este tipo son conocidas como rendición de cuentas horizontal de balance. A este tipo particular de rendición de cuentas se le han señalado varias limitaciones, entre ellas que:

a. Las instituciones de balance (ejecutivo, legislativo y judicial) suelen actuar de manera reactiva e intermitente ante presuntas agresiones de otras agencias.

b. Las acciones de las instituciones de balance tienden a ser muy dramáticas, con una alta visibilidad y costo (económico y político).

c. Los actores de estos conflictos suelen estar motivados por intereses partidistas, lo que dificulta la solución del conflicto.

d. Las instituciones de balance son un instrumento demasiado torpe para la creciente complejidad de las agencias y sus políticas (O'Donell, 2001, p. 9).

La constatación de estas limitaciones condujo a la creación de agencias con rendición de cuentas horizontal asignadas, tales como: defensores del pueblo (ombudsman), contralorías, auditorías, fiscalías, controladores y similares. Estas agencias están legalmente encargadas de supervisar, prevenir, promover sanciones o, directamente, sancionar acciones u omisiones de otras agencias estatales, nacionales o subnacionales, que sean consideradas como corruptas o presuntamente ilegales. Las agencias asignadas no fueron creadas para promover balances generales de poder, sino previendo riesgos de transgresión y/o corrupción. Es por ello que, en principio, tienen varias ventajas respecto a las agencias de balance. Entre ellas se destaca que:

Pueden ser proactivas y continuas en su actividad y, por lo tanto, más efectivas en prevenir o disuadir acciones ilegales de las agencias que supervisan.

Las acciones que realizan están motivadas por criterios profesionales, antes que partidarios o políticos.

Debido a su carácter continúo y profesionalizado, pueden desarrollar capacidades que les permitan examinar cuestiones complejas de políticas estatales ( $\mathrm{O}^{\prime}$ Donell, 2001, p. 9).

En resumen, la rendición de cuentas horizontal implica la existencia de:

"Agencias estatales que tienen autoridad legal y están fácticamente dispuestas y capacitadas para emprender acciones que van desde el control rutinario hasta sanciones penales o incluso el impeachment, en relación con actos $\mathrm{u}$ omisiones de otros agentes o agencias del Estado que pueden ser presuntamente calificadas como 
ilícitos" (O’Donell, 2002, p. 87).

De esta manera, se distinguen también las dos direcciones en las que puede entrar en juego la rendición de cuentas horizontal, siendo estas: en casos de transgresión ilegal de una agencia estatal sobre la autoridad de la otra y en casos de que los funcionarios públicos intenten obtener ventajas ilícitas para sí o para sus asociados, es decir, corrupción.

Sin embargo, la efectividad del control del poder del Estado no se consigue solamente con la autorización legal de determinadas agencias estatales y que estas estén capacitadas y dispuestas a actuar, sino que es necesario realizar algunas conjugaciones. En primer lugar, es imprescindible la existencia de una red de agencias estatales, donde se incluyan los tribunales superiores del poder judicial, que esté comprometida con la preservación y acatamiento de la rendición de cuentas horizontal, inclusive, en caso de necesidad, contra los más altos poderes del Estado. Y, en segundo lugar, es necesario que la rendición de cuentas horizontal se articule e interrelacione con otras formas de rendición de cuentas, como la vertical y la social. Además de los mecanismos de control vertical y horizontal, las investigaciones han apuntado la necesidad de instaurar controles menos tradicionales, como es el caso de los mecanismos de rendición de cuentas transversales o diagonales. Seguidamente nos referiremos a estos.

\section{Rendición de cuentas diagonal}

Las deficiencias en los sistemas de rendición de cuentas convencionales tales como: el secretismo en los procesos de auditoría, las revisiones ineficaces de las políticas por los parlamentos, la información incompleta del electorado, las demoras excesivas en los tribunales y las sanciones inadecuadas ante el irrespeto de normas o reglas administrativas; han ejercido una fuerte presión para mejorar las rendiciones de cuentas horizontal y vertical. Todo esto llevó a Goetz y Jenkins (2001) a plantear una forma híbrida de rendición de cuentas, conocida como «diagonal».

Uno de los grandes problemas de la rendición de cuentas horizontal es la negación del acceso de los actores no estatales o ciudadanos, a sus procedimientos. Los burócratas, auditores y jueces, usualmente, se aíslan de los ciudadanos para protegerse de intromisiones en sus intereses particulares -de cualquier tipo- y para preservar la noción de guardianes del interés público ante «maquinaciones egoístas» de actores políticos no estatales y grupos sociales influyentes. Por otra parte, también existen instituciones, tanto formales como informales, que distancian a los funcionarios de los ciudadanos, tales como: reglas de confidencialidad, uso de lenguajes impenetrablemente técnicos, o la distancia física de las oficinas gubernamentales de la gente común. Todo esto puede y suele ayudar a ocultar el abuso de lo público en la obtención de beneficios personales o rentas políticas.

La sociedad civil quedó invisibilizada durante mucho tiempo en la mayoría de las recomendaciones de fortalecimiento de las agencias de rendición de cuentas interestatales, tanto desde la academia, como desde las organizaciones internacionales. Esto es evidente, ya que la participación directa de los ciudadanos en el trabajo sustantivo realizado por las instituciones de control horizontal, se considera aún «novedoso», en el seno de las discusiones sobre gobernabilidad democrática. Todo ello ha relegado a los ciudadanos y sus asociaciones a la función tradicional de control vertical electoral; y totalmente desprovistos de información gubernamental detallada que les permita contrarrestar, o verificar, la base sobre la cual las instituciones públicas toman las decisiones. Una pregunta se sigue imponiendo, y está relacionada con que, si las instituciones horizontales son los nervios y los músculos del control de la corrupción, ¿por qué los funcionarios públicos les permitirían funcionar con eficacia?

Esta pregunta refleja un reclamo histórico del activismo participativo; sin embargo, no tiene una respuesta acabada. Goetz y Jenkins (2001) presentan mediante dos estudios de caso, formas de control democrático híbridas, o diagonales, que pueden ser útiles para evitar el abuso de poder por parte de los funcionarios públicos. En primer lugar, explican que el poder judicial, en ciertas ocasiones, puede ser un caso interesante de este tipo de control democrático. El poder judicial es una institución de supervisión pública que opera usualmente en el modo de rendición de cuentas horizontal; pero cuando acepta casos presentados por miembros de la ciudadanía contra alguna agencia del Estado, la orientación de la judicatura puede cambiar y transformarse en un mediador entre los ejes verticales y horizontales. Este es uno de los medios que pueden utilizar los ciudadanos para comenzar a ingresar en el proceso horizontal de monitoreo del gobierno. $\mathrm{Si}$ proceden con las herramientas disponibles a través de litigios ciudadanos individuales o de grupos de activistas, el proceso de búsqueda de hechos puede conducir 
al descubrimiento y disponibilidad de información gubernamental, así como de un escrutinio detallado de sus decisiones; lo que quizás, de otra manera, no hubiese sido posible.

En segundo lugar, los autores exponen otra forma de control diagonal que es la que se realiza a través de las observaciones o veedurías ciudadanas. Esta forma de control permite que las personas participen directamente en la vigilancia, fiscalización y control de la administración pública. Sin embargo, para que este tipo de control asuma una forma institucional más prometedora, hay cinco características claves que teóricamente lo podrían permitir:

a. Estatus legal para los observadores no estatales dentro de las instituciones de supervisión del sector público.

b. Presencia continua de estos observadores a lo largo del proceso del trabajo de la agencia estatal.

c. Procedimientos bien definidos para la realización de encuentros entre ciudadanos y actores del sector público.

d. Acceso estructurado al flujo de información documental oficial.

e. El derecho de los observadores a emitir informes de disconformidad con la gestión de la agencia, directamente a los cuerpos legislativos (Goetz y Jenkins, 2001, p. 369).

Estas condiciones para la participación ciudadana en el Estado se enfrentan a algunas barreras. En primer orden está la tendencia del Estado ha evitar, cada vez más, el surgimiento de nuevas formas de participación que involucren a los ciudadanos en la evaluación de sus políticas. Es así que las formas diagonales de rendición de cuentas se enfrentan a una dura competencia con el propio Estado. Este Estado y sus élites, motivados por el deseo de evadir mecanismos de rendición de cuentas horizontales, argumentan que confían más en formas modificadas de control (vertical) que vinculan directamente al Estado con los ciudadanos y sus grupos. Algunas de estas prácticas incluyen jurados ciudadanos, foros de consulta, grupos focales y cartas ciudadanas, las cuales suelen carecer de poder de decisión. Dan "voz" a ciertos grupos excluidos, pero casi nunca proporcionan a los participantes, el derecho a una respuesta o explicación de los funcionarios y menos aún, obligan al Estado a reparar o compensar los daños ocasionados.

La segunda restricción a la proliferación de estos mecanismos diagonales para la inclusión formal de ciudadanos en procesos de supervisión estatal, es el problema de la ampliación. Por lo general, las formas híbridas de control operan en niveles locales. Además, estas formas institucionalizadas de vigilancia de la sociedad civil se pueden enfrentar a un problema adicional de legitimidad, una vez que esta se ponga en tela de juicio, a partir de que el ciudadano pasa a ser observador «oficial» del Estado.

\section{Consideraciones finales}

La rendición de cuentas es un concepto central para la gobernanza. Aunque tradicionalmente se encuentre estrechamente asociado con la gobernabilidad democrática, la rendición de cuentas también puede ser importante para otros tipos de sistemas políticos. Tanto para sistemas democráticos como no democráticos, la rendición de cuentas es un medio útil para identificar el éxito y el fracaso de acciones pasadas. Esta identificación también puede servir como una herramienta para inducir la reflexión y el aprendizaje; sobre todo al tener la capacidad defuncionar como formas de retroalimentación en busca de que los gobiernos, las agencias estatales y los funcionarios públicos sean más efectivos al cumplir sus promesas. Las revisiones del desempeño, por ejemplo, pueden inducir a muchos funcionarios a reconsiderar y ajustar sus políticas. Además, la naturaleza pública del proceso de rendición de cuentas enseña a otros funcionarios, en posiciones similares, $\mathrm{o}$ a futuros servidores públicos, a que conozcan lo que se espera de ellos, lo que funciona y lo que no.

Ante foros legales y administrativos tales como tribunales, auditores, defensores del pueblo, observadores y controladores, la rendición de cuentas es un mecanismo importante para prevenir y detectar la corrupción, así como el abuso de los poderes públicos. De igual manera, también puede ser un medio para asignar responsabilidad por fallas o, menos frecuentemente, identificar a las personas responsables del éxito y pensar en multiplicar su experiencia para un mejor desempeño del sistema.

Sin embargo, y como reto, hay que tener en cuenta que un control democrático demasiado riguroso puede limitar la creatividad de los administradores públicos y puede convertir a las agencias en burocracias obsesionadas con las reglas. Del mismo modo, un excesivo «énfasis en la integridad administrativa y en el control de la corrupción, puede llevar a un procedimentalismo que obstaculice seriamente la reflexividad» (Bovens, 2010, p. 
956) y, por lo tanto, también la eficiencia y efectividad de las organizaciones públicas.

En este trabajo se visitaron algunas de las diversas formas de rendición de cuentas que ha trabajado la literatura especializada en los últimos años. Apoyándonos fundamentalmente en lostrabajos de Guillermo O'Donell, Andreas Schedler, Enrique Peruzzotti, Catalina Smulovitz y Adam Przeworski, es posible concluir que hoy no solo es importante fortalecer los mecanismos tradicionales, sino que es imprescindible generar innovaciones de control democrático y entender a la rendición de cuentas, como una virtud personal y organizacional del sistema político.

\section{Referencias}

1. Bovens, M. (2007). Analysing and Assessing Accountability: A conceptual Framework. European Law Journal, 13(4), 447-468. doi: doi.org/10.1111/ j.1468-0386.2007.00378.x

2. (2010). Two concepts of accountability: accountability as a Virtue and as a Mechanism. West European Politics, 33(5), 946-67.doi: doi.org/10.108 $0 / 01402382.2010 .486119$

3. Centro Latinoamericano de Administración para el Desarrollo (2016). Carta Iberoamericana de Gobierno Abierto. Bogotá: CLAD.

4. Coppedge, M., Gerring, J., Altman, D., Bernhard, M., Fish, S., Hicken, A., y Semetko, H. A. (2011). Conceptualizing and measuring democracy: A new approach. Perspectives on Politics, 9(2), 247-267. doi:10.1017/S1537592711000880

5. Cornwall, A. y Coelho V. S. (2007). Space for change? The politics of participation in new democratic arenas. En Cornwall, A. y Coelho V. S. (Eds.), Space for change? The politics of citizen in new democratic arenas (pp. 1-29). London: Zed Books.

6. Dagnino, E. (2004). Sociedad civil, participación y ciudadanía: ¿de qué estamos hablando? En: Mato, D. (coord.). Políticas de ciudadanía y sociedad civil en tiempos de globalización. Caracas: Faces/ Universidad Central de Venezuela.

7. Dahl, R. A. (1989). Democracy and its critics. New Haven: Yale University Press.

8. Dubnick, M. J. (2007). Situating Accountability: Seeking Salvation for the Core Concept of Modern
Governance. Melvin J. Dubnick (blog), 14 de mayo. http://mjdubnick.dubnick.net/papersrw/2007/ situate2007.html

9. (2014). Accountability as a cultural keyword. En Bovens, M., Goodin, R. E. y Schillemans, T. (Eds.), The Oxford Handbook of Public Accountability (2338). Oxford: Oxford University Press.

10. Fernández-Albertos, J. (2005). Dividir lo Indivisible. Separación de poderes y soberanía popular en James Madison. Revista de Estudios Políticos (nueva época), $128,293-316$

11. Goetz, A. M. y Jenkins, R. (2001). Hybrid Forms Of Accountability: Citizen engagement in institutions of public-sector oversight in India. Public Management Review, 3(3), 363-383. doi: 10.1080/14616670110051957

12. Gurza, A. y Isunza, E. (2010). Precisiones conceptuales para el debate contemporáneo sobre la innovación democrática: participación, controles sociales y representación. En La innovación democrática en América Latina. Tramas y nudos de la representación, la participación y el control social. México: Centro de Investigaciones y Estudios Superiores en Antropología Social.

13. (2011). A trama da crítica democrática: da participação à representação e à accountability. Lua Nova: Revista de Cultura e Política, (84), 95-139. doi:10.1590/S0102-64452011000300005

14. (2015). Representación y participación en la crítica democrática. Desacatos. Revista de Ciencias Sociales, (49), 10-27.

15. Hanson, R. (1989). Democracy. En Ball, T., Farr, J., \& Hanson, R. L. (Eds.), Political innovation and conceptual change (68-89). Cambridge: Cambridge University Press.

16. March, J. y Olsen, J. (1995). Democratic Governance. New York: Free Press.

17. Monsiváis, A. (2015). El debate sobre la construcción de la democracia: aportaciones analíticas en clave latinoamericana. Desacatos. Revista de Ciencias Sociales (49), 82-91.

18. Mulgan, R. (2003). Holding Power to Account. Accountability in Modern Democracies. London: 
Palgrave Macmillan.

19. O'Donnell, G. (2001). Accountability horizontal. POSTData, Revista de Reflexión y análisis político, 7, 11-34.

20. (2002). Acerca de varias accountabilities y sus interrelaciones. En Peruzzotti, E., y Smulovitz, C. (Eds), Controlando la Política. Ciudadanos y Medios en las Democracias Latinoamericanas (87-102). Buenos Aires: Grupo Editorial Temas.

21. (2007). Disonancias. Críticas democráticas a la democracia. Buenos Aires. Prometeo libros.

22. Olsen, J. (2017). Democratic accountability, political order, and change. Oxford: Oxford University Press.

23. Peruzzotti, E. y Smulovitz, C. (2002). Accountability social: la otra cara del control. En Peruzzotti, E., y Smulovitz, C. (Eds), Controlando la Política. Ciudadanos $y$ Medios en las Democracias Latinoamericanas. Buenos Aires: Grupo Editorial Temas.

24. Peters, G. (2007). Performance-Based Accountability. En Performance accountability and combating corruption. Washington D.C.: The World
Bank.

25. Przeworski, A. (2002). Accountability social en América Latina y más allá. En Peruzzotti, E., y Smulovitz, C. (Eds) Controlando la Política. Ciudadanos $y$ Medios en las Democracias Latinoamericanas. Buenos Aires: Grupo Editorial Temas.

26. Schedler, A. (2004). ¿Qué es la rendición de cuentas? CIDE: www.iepcjalisco.org.mx/sites/default/files/ que_es_la_rendicion_de_cuentas

27. Manin, B., Przeworski, A., Stokes, S. C. (2002). Elecciones y representación. Zona abierta, 100-101, pp. 19-50.

28. Strom, K. (2000). Delegation and Accountability in Parlamentary Democracies. European Journal of Political Research, 37, 261-89.

29. (2003). Parlamentary Democracy and Delegation. En Delegation and Accountability in Parlamentary Democracies. Oxford: Oxford University Press.

30. Thede, N. (2010). Derechos Humanos, nuevas democracias y rendición de cuentas. En: Democratización, rendición de cuentas y sociedad civil. México: CIESAS / Porrúa. 